\title{
Measuring History: An Active Learning Exercise to Bridge Interdisciplinary Silos and Promote Sustainability in Architectural Education
}

\author{
B.D. WORTHAM-GALVIN \\ Clemson University
}

\section{KALINA VANDER POEL}

Mosaic Architecture

\begin{abstract}
A survey conducted by Sergio Altomonte $(2014,145)$ reported respondents' view that architectural education as a whole does not embrace sustainability as "existing educational programmes do not yet fully support the promotion of sustainable design." Comments such as these speak to the larger issues found in architectural pedagogy and paradigm. As such, this paper argues one reason sustainability has yet to be widely implemented into architectural education is because silos within architectural education impede advancements in sustainable practices. These silos, in turn, dissuade alternative teaching methods from entering pedagogy in non-studio courses. In order to address this issue, this paper outlines a recent attempt to bridge interdisciplinary silos found within architectural education through an active learning exercise that synthesized qualitative, humanities-based methods with quantitative, science-based practices.
\end{abstract}

The central point about architecture is the need to bring things into relationship with each other-to see and understand it's cohesive manner.

-Leslie Martin (2016, 190)

\section{INTRODUCTION}

There is a recognized need for architectural education to embrace sustainability into curricular and co-curricular activities as (1) the building sector (currently) negatively impacts the environment, (2) buildings increasingly impact human health and wellbeing, and (3) there is a market demand for sustainable/green buildings. Given these geopolitical realities, future architects must be prepared to participate in a work environment that recognizes sustainability as a driving factor in the profession. A survey conducted by Sergio Altomonte, et al. $(2014,145)$ reaffirms the growing acceptance of sustainability in the architectural profession as can be seen through

\section{COREY GRIFFIN}

Pennsylvania State University comments such as, "...at a global level, there is a growing awareness and interest in the themes of sustainability, as well as an acceptance that it offers the potential to serve as a source of creative inspiration to the design process."

It is unfortunate, then, when Altomonte $(2014,145)$ goes on to summarily report survey respondents' view that architectural education as a whole does not embrace sustainability....".existing educational programmes do not yet fully support the promotion of sustainable design, suggesting significant room for improvement." Rather than condoning the incremental progress that has been made-as can be seen through partnerships with non-profit organizations, local professionals, and initiatives such as the 2030 curriculum project-comments such as these speak to the larger issues found in pedagogy and paradigm. Specifically, this paper argues one reason sustainability has yet to be widely implemented into architectural education is because silos within architectural education impede advancements in sustainable practices. These silos, in turn, dissuade alternative teaching methods from entering architectural pedagogy in non-studio courses.

In response, this paper highlights a recent attempt to bridge interdisciplinary silos found within architectural education through an active learning exercise that synthesized qualitative, humanities-based methods with quantitative, science-based practices. In spring 2016, architectural history students at Portland State University School of Architecture were tasked to go into historic buildings with building science tools and record specific building performance measurements. This exercise was tied to two other humanities-based research assignments which investigated (1) the architectural form and aesthetics and (2) the historical, cultural and environmental context for the same building. For students, the exercise revealed not only how historic buildings perform and the presence/lack of sustainable design decisions, but it also engendered a relationship that 
exists between building science and architectural history/theory as they were asked to integrate all three pieces of research into a holistic portrait of the work of architecture. For educators, the exercise exemplifies the possibility to utilize active learning exercises in a large lecture architectural history survey course as a means to both promote sustainability and bridge silos in architectural education. This is important because once the gap is bridged and alternative teaching methods are more fully supported, architectural education can embody an integrated, interdisciplinary, and interactive pedagogy that can inherently support sustainability.

\section{METHODS AND PEDAGOGIES AND SILOS IN ARCHITECTURAL EDUCATION}

Architecture embraces active learning in the pedagogy of the studio. Taken from disciplines of the arts and guild traditions, studio is a mentorship-style instruction where students often work one-on-one with faculty, and is both praised and criticized for the pedagogical approach, learning environment, and resulting culture. Architecture courses outside of studio are similar in instruction format to courses in many disciplines in higher education including lectures, seminars, and labs. As such, it is subject to similar pitfalls and arguments for reform. Architecture, while having a slightly unique course structure, is no exception when it comes to educational reform; particularly with the siloing of disciplinary knowledge within architectural discourse.

Carolin Kreber (2009) defines the silo effect as a result of subjects and areas of research being compartmentalized into disciplines; Michael Daughtery $(2013,10-11)$ notes these silos have been present in American educational institutions for more than a century. Thus, each discipline has its own particular "way to think," which results in insular approaches and narrow-focused solutions to problem solving. Architectural education has the unfortunate state to contain two insular silos within a single discipline: (1) building science and (2) architectural history/theory. There are also a series of subdisciplines, and therefore sub-silos, within architecture. These include, among others, materials study, graphics, structures, and computer modeling. If the landscape of architectural education were silos in an agrarian landscape, each sub-discipline would not only be an insular silo, it would be a silo with varying distances from other silos. If we were to apply distance between silos as a translation in the distance between the sub-disciplines within academia, the architectural history/theory silo and the building science silo would be as far apart as possible, with the remaining sub-disciplines somewhere in between.

In architecture the division between history and building science is seen as so inherent within the current paradigm of architectural education that few examples can be found that bridge these silos. There are those, like Ping Xu (2012) that argue other types of interdisciplinary activities can and should occur. Others-e.g. Catherine Wetzel (2012), Marcus Grant et al (2015) or David Lee Smith (1987)-use studio as a platform to introduce sub-discipline or interdisciplinary topics such as structure, technology, public health, etc. Nevertheless, the authors have yet to find publications highlighting collaboration outside of studio courses and particularly between building science and architectural history/ theory. This isn't to say that those within the sub-disciplines of history and building science do not collaborate; they just do not collaborate with each other. It is not unusual for building science courses, professors, and student organizations to work closely with engineers and explore a problem or project in an interdisciplinary fashion. Architectural historians and theorists are known to work with disciplines that reside in the humanities and social sciences. Yet the chasm between those whose methods rely on measurement and quantification and those who rely on hermeneutics and interpretation remains vast within architectural discourse.

Thus, the current disconnecting link between sub-disciplines of history and building sciences in architecture and their respective interdisciplina-ry partners is the mode of research. Building sciences largely relies on the scientific method, measuring and quantification when conducting research while history utilizes written, spoken and visual artifacts and engages in interpretation, description and other qualitative means. It is this mode of research that, arguably, created the sub-disciplinary silos to begin with as Mark Donofrio (2013) notes: "This wide spectrum of possibilities available to those exploring architectural research as well as the fragmented nature of the current building industry has led to discipline silos that hinder collaborative opportunities."

This isn't to say sub-disciplines do not exist in other disciplines, just that it is problematic for architecture as we move towards a sustainability driven future. Sustainability is naturally "transdisciplinary," meaning it is a problem that goes beyond, or transcends, the boundaries of a particular discipline. Sustainability falls into what Kreber $(2009,25)$ refers to as "Mode 2" form of knowledge production, where knowledge is seen to originate not in disciplinary problems but within the framework of real life application where solutions are required for complex problems, demanding different forms of expertise and skill sets than those typically associated with academic study of a particular discipline. The application of knowledge is as important as its production, and knowledge is interdisciplinary.

As such, it is critical more than ever, that architectural education addresses the current state of insular sub-disciplines through curricular reform.

Ernest Boyer started publishing significant work on educational reform in the 1980s with the Boyer Report published in 1995. The overarching declaration to these documents 
(Boyer, 1990) is that education must shift from traditional pedagogical approaches, such as large, lecture-based courses, to a pedagogy and campus environment that integrates and promotes interdisciplinary study.

While Boyer was arguing for change at a university scale, D.A. Kolb developed the well-known four categories of experiential learning in the 1970s, and continues to question the modes and methods of learning (Kolb 1984, 2005). Kolb's experiential learning requires professors to generate coursework where students intentionally learn by doing with time for reflection and discussion i.e.: students must interact with a concept in the physical world and be able to turn the interaction into a genuine learning experience. This necessarily pulls students (and professors) out of the traditional lecture-based learning format and into a more engaged and interactive classroom.

Simultaneous to the development of experiential learning theory and progressive ideas in the Boyer Report, a concern for the environment seeped into social, political, and economic spheres. Starting as early as the 1960s, sustainability grew as an actionable issue promoting societal shifts in stewardship, and by the early 1990s it reached a point to influence education policy and pedagogy (De Haan 2006). Since its inception, sustainability education includes priorities such as independent inquiry and acquisition of information, cooperation and communication, big-picture thinking and foresight (De Haan 2006, Brundiers 2010). Interdisciplinary activities receive particular emphasis in sustainability education as "problems of ecology and sustainability can no longer be approached from any single specialized field of study (De Haan, 2006, 22)." In addition, sustainability education has a strong preference for an educational approach that is competency-oriented. As De Haan notes:

Competence-oriented educational concepts focus on output, whereas conventional syllabuses and didactic approaches focus on input: the latter raises the question about which subjects pupils should study. By contrast, the output approach asks what problem-solving strategies, concepts and abilities for social action they should have. $(2006,22)$

Overwhelmingly, these all speak to an educational paradigm that inherently includes integration, interdisciplinary activities, elevates students from listeners to participants with a high level of communication and community in the classroom. The pedagogy is one of hands-on, research-based, and inquiry-based learning methods (Boyer 1990 \& 1998, Kolb, de Haan 2006, Brundiers 2010, Altomonte 2010 \& 2014, Salama).

While arguments for teaching with regards to experiential learning, the Boyer Report, and sustainability have existed for over 20 years, the new educational models are still not widely implemented. The result, therefore, is a pedagogical stalemate where sustainability education, experiential learning, and the Boyer Report stay theories rather than directly influence and impact students' education.

\section{METHODOLOGY AND IMPLEMENTATION OF AN ACTIVE LEARNING EXERCISE}

Founded in 2015 by Corey Griffin, BUILT (Building Science Lab to Advance Teaching) is a building science research lab that provides green building research experience to students, with particular emphasis on lower-level undergraduates. BUILT's philosophy holds that students will develop a greater understanding of the relationship between design and building performance when they conduct research on the built environment. BUILT supports student progression from basic skills to higher level research and analysis such as systems education and simulation analysis with the intent that a more robust and deeper engagement with building science research will foster innovations for sustainability.

To promote new forms of learning, BUILT specifically focuses on introducing sustainability competencies throughout the undergraduate experience including lower level and upper level coursework. Relevant competencies of sustainability for architecture students include: (1) the need to be exposure to a diversity of opinions, perspectives, facts and strategies, (2) the need to be able to link knowledge and action in such a way that it provides a greater understanding (both theoretical and technical) of the built environment, and (3) the need to be able to successfully collaborate in teams in, around, and of different knowledge communities.

Corey Griffin implements BUILT's philosophy and goals by providing students and faculty access to a physical lab, a tool library, and dedicated staffing (figure 1). In addition, BUILT has an extensive simulation software library that students can "check out" through reserving the use of a lab computer.

BUILT supports new course modules (partnerships with firms for example), in-class exercises which utilize active learning, as well as teaching philosophy; and, therefore, acts as a resource for both faculty and students. It specifically responds to the lack of resources and the current inter-disciplinary barriers that exists in architectural education by providing time, tools, and knowledge to faculty. It also addresses the current inter-disciplinary barriers that exist in architectural education by educating students about building science within an existing curriculum. BUILT is particular on which courses it partners with. The course must actively combat disciplinary silos, and the course must be either interdisciplinary in nature (comprised of arch and non-arch students or taught outside the school of architecture), or be a non-building science sub-discipline course. 


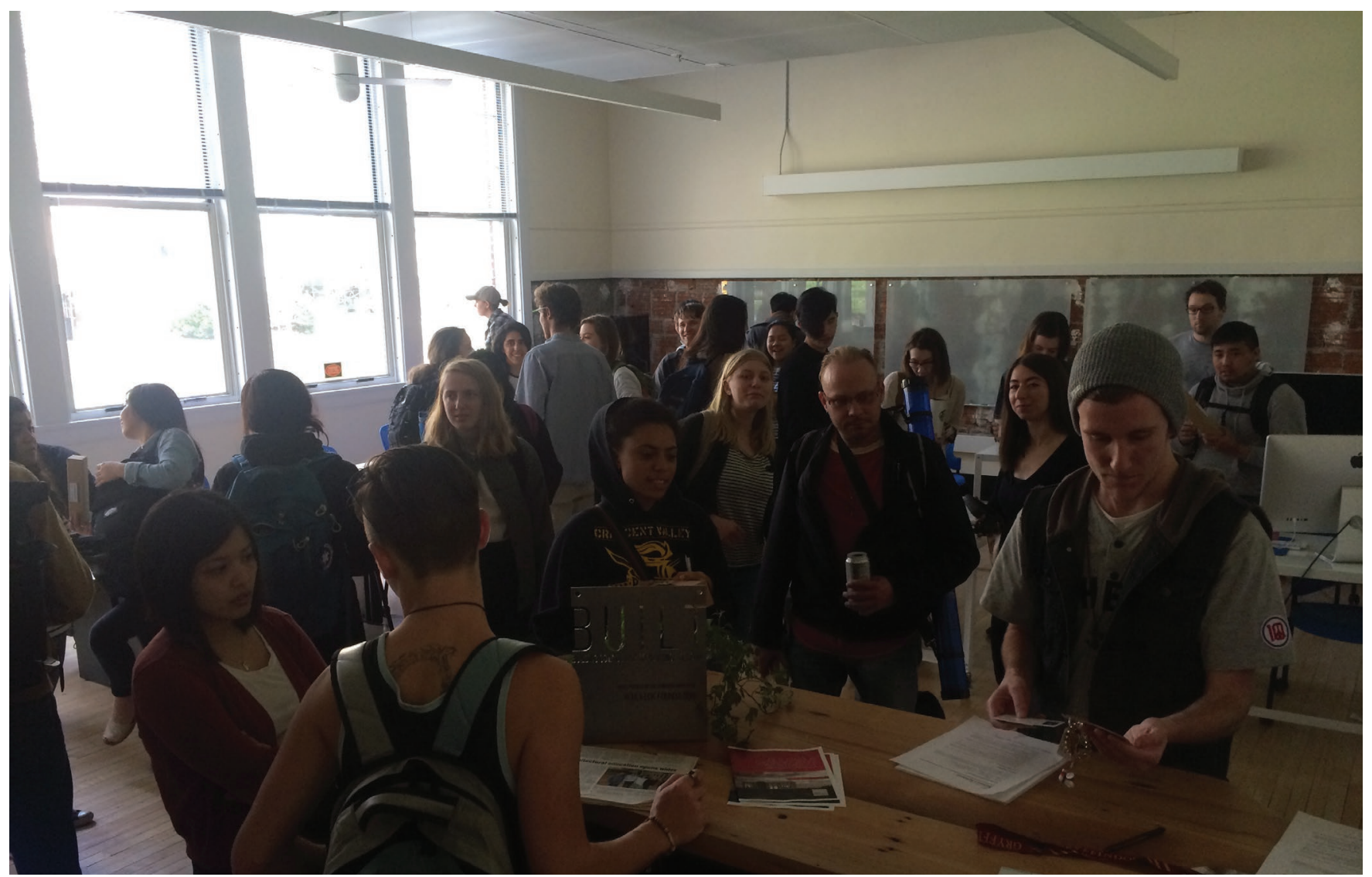

Figure 1. Students check out equipment from the tool lending library for their Measuring History project. Image taken by author

In Spring 2016, BUILT partnered with Associate Professor B.D. Wortham-Galvin to deploy an active learning component as an in-class exercise for an existing undergraduate history survey course. The active learning exercise proposed to have students collect building performance measurements on pre-modern, modern, postmodern and contemporary buildings in order to engender a greater discussion on the relationship between building performance, architectural form and cultural context. Sustainability competencies targeted for this exercise were strategic knowledge and collaboration. The strategic knowledge cluster was specifically focused on exposing students to an alternative perspective of the subject. In this case, students were exposed to and expected to look at historic buildings through the lens of building science by going out into the field to collect data and generate a comprehensive understanding of the assigned building. Building measurements, their analysis, and synthesis with the larger story were done collectively, thus satisfying a collaboration sustainability cluster.

The exercise was developed in such a way as to promote the following sustainability objectives: diversity of perspective and strategy, link knowledge and action, hands on experience, and teamwork as well as (to a limited degree) testing validity. In addition, building science methods including hypothesis, testing hypotheses through observation, data collection, and analysis as well as reporting on findings.

\section{FINDINGS}

During the initial introductory phase of the partnership, BUILT would act in its capacity as a resource in the following ways: (1) assist with the development of material and researching/ purchasing/training of tools; and, (2) instruments checked out from the tool library would be used by students as the method for data observation. In order to create the material for the exercise, the history team developed a list of local buildings appropriate for all of the exercise. The buildings had to be historically relevant in architectural form and cultural context and fit within one of the three time periods of "premodern," "modern," or "after modern" (the latter phrase referring to both postmodern and contemporary buildings). Time periods roughly correlate with the advancement of building systems from pre-centralized hvac system, heavy reliance on hvac and artificial lighting, and the green movement respectively. Buildings also were close in proximity to ensure all within a similar microclimate environment and exposed to similar climatic conditions over time. Additionally, preference was given to buildings that were institutional in nature and open to the public.

Fifteen buildings-constructed from 1900 to 2010-were chosen based on the guidelines established for selection. Sixty-five students were divided into groups of four to five students to perform three assignments for the course: (1) 
architectural description: (2) historic and cultural context; and (3) building performance measurements. Once selected, BUILT staff visited each building to determine that viable building performance criteria that could be taken. During the visit staff also determined access points for students and selected an ideal room for data collection. Building performance measurements included determining the viability of studying the following metrics: Daylight intensity, Artificial light intensity, Light color, Ultraviolet A, Sound, Ambient Air Temperature, Surface Temperature, Wind/Air circulation, and Heat transference.

It was determined after the initial building visits, that a collection of similar building performance measurements would be preferred for the exercise with the theory that students would be able to compare the same data collection method and note discrepancies between collection as a possible side effect of historic context. As such, Light intensity, UV-A, Sound, Surface Temperature, and Ambient Air Temperature were selected as the performance criteria for each building. The selection of these building performance measurements was beneficial as it not only had the likelihood of generating interesting findings, but they could all be measured utilizing the same brand of tools: Vernier (figure 2). For the collaboration with BUILT, student teams which individual would study which building performance measurement. The intent was for each student to become educated in that particular building science phenomena and become the resident "expert" within the group.

To assist with success of the exercise, BUILT staff created three types of course material. The first was a general description sheet that introduced students to their building. The second was a general information sheet introducing students to building science methods such as forming a hypothesis and quantitative analysis. It also included information on the student's particular building performance measurement and corresponding tool for data collection.

The third was a template of the plan of the room with boxes indicating where students were to take measurements within the specified room.

Per student experience, the measuring exercise was conceptually broken into three phases. The first phase included the introduction of the assignment to the preexisting groups. Each group was told they were to collect building performance measurements in order to understand how their historic building is performing relative to metrics currently placed under the rubric of sustainability. Associate Professor Wortham-Galvin also gave a lecture on the relationship between building performance, building technology, and human comfort throughout the time periods pertinent to the course (the pre-modern era through the contemporary).
To mark the beginning of the second phase, a second in-class lecture introduced students to the tools and equipment the students would use at their building. Vernier tools were brought to class for demonstration purposes. The second course material was distributed to students, and students were asked to select which measurement they would like to observe. After the lecture BUILT staff went to each group to prompt initial thoughts on building science, the process of conducting research, as well as answer any questions related to the exercise. During phase two students were expected to observe and collect data at their assigned building.

During phase three, students returned to class with recordings of the specified data. The entire duration of class was dedicated to the analysis of the data collected. Students met in groups and discussed their individual findings. BUILT staff went around to each group to discuss findings, determine if any unusual data was recorded, respond to questions and suggest whether the group should revisit the building for additional data collection. Within each group, students combined data to develop a comprehensive package on the basic building performance.

The course concluded with each group synthesizing the three assignments-(1) architectural description, (2) historic, cultural and environmental context, and (3) building performanceand reporting information on their building, collectively researched, through an in-class slide presentation (figures 3-5). The intent of the in-class presentation was to provide opportunity for public speaking as well as for other groups to hear and compare the presented findings with their own and to engage in a broader conversation about architectural design and performance from the nineteenth century to today.

Throughout the development and deployment of the exercise, there existed a "front of house" and "back of house." BUILT primarily resided in the "back of house" by supporting essential training on building science education, research, and related tool use. The History team acted as the "front of house." Consistency of leadership and course direction was maintained throughout the exercise, with administration, grading and evaluation of student success staying with the History team. The ease of recurring deployment was a key factor in the design of the exercise; and, in fact, with slight revision the exercise was repeated by Mosaic Architecture and BUILT the following year (Spring 2017) for 90 students using 18 buildings.

\section{CONCLUSION}

Those who possess this competence can help, through their active participation in society, to modify and shape the future of society, and to guide its social, economic, technological and ecological changes along the lines of sustainable development.

-Gerhard de Haan $(2006,22)$ 


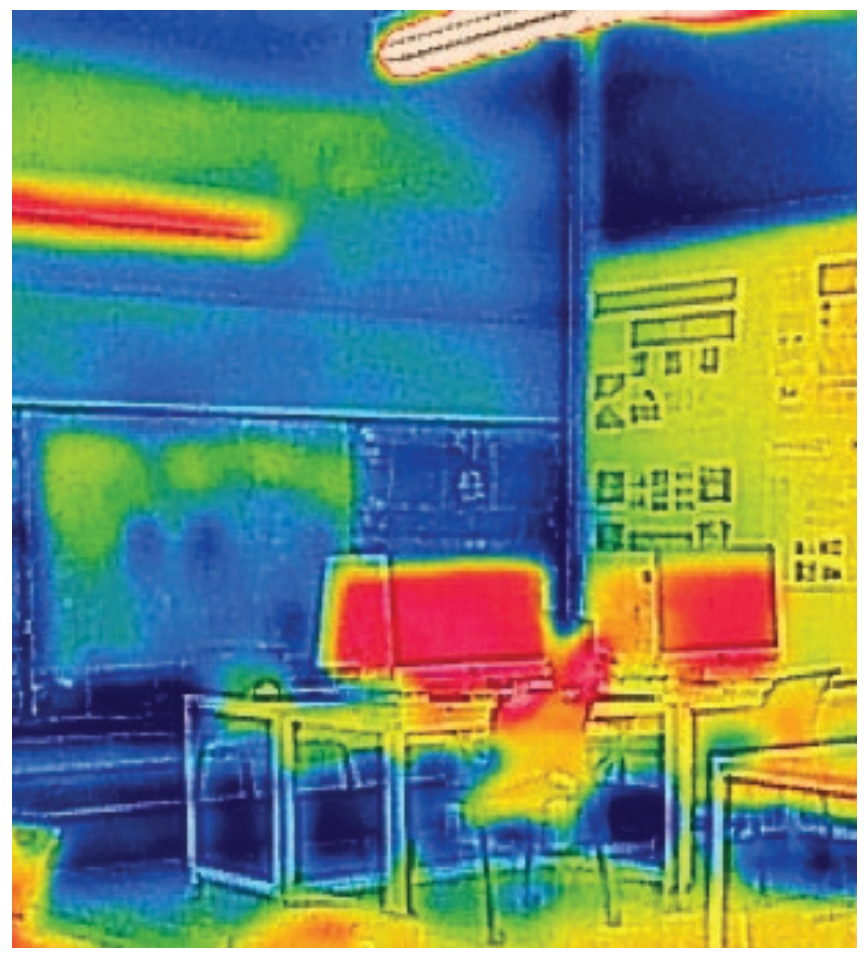

Figure 2. Sample image from the Venier tool being used to measure temperature for the Measuring History project.

The in-class exercise was evaluated for its ability to meet the original proposal goals and satisfy BUILT's mission. In addition, the assignment was evaluated for viability in acting as means for integrating sustainability into architectural education and for its effectiveness in removing interdisciplinary barriers within architectural education. Evaluation of meeting proposal goals and satisfying BUILT mission was determined through interviews, discussions, surveys, student performance, and documented student engagement. Through the structured course material, students participated in an active learning exercise that utilized tools and building science methods to investigate phenomena of the built environment. The nature of the exercise promoted sustainability objectives. Students worked in teams while being exposed to different perceptions and approach (building science) to a subject (history).

Anticipated impacts included a greater perception of course subject and new knowledge in building science methods. Through interaction, discussion, and documenting student performance, the anticipated impact of the exercise was achieved. Additionally, some unanticipated impacts include student inquiries in building science methods beyond the specified exercise and course. The students that went through the exercise returned to BUILT to ask questions and check out tools for self-directed inquiry in courses such as design studio. This unanticipated impact reveals not only a perceived value and retention of the original active learning exercise, but it also suggests a growing appreciation and understanding of building science and sustainability objectives such as testing validity to impact students educational experience.
Large, lecture-based courses (like architectural history) can be particularly difficult to introduce alternative pedagogical movements. That being said, while difficult, it is possible. As Richard Yuretrich (2004) notes, "Higher-order reasoning or critical thinking can be woven into a large-enrollment class, but their inclusion requires moving beyond the traditional lecture and exam mode. Active learning methods offer the best solution." The collaboration between BUILT and history faculty demonstrated the ability to innovate architectural pedagogies by closing the gap between quantitative measurements and qualitative hermeneutics in a synthetic and holistic manner. History was no longer siloed as a isolated (and potential irrelevant) requirement but a means of comparative inquiry into sustainable building practice between past, present and future. The application of historic research with hands-on building measurements allowed students early in their academic career to work in teams on anticipatory and action-oriented competencies (Brundiers, de haan) to establish their own holistic frameworks for understanding architecture and its intersection with sustainability. In this way, the exercise attacks head-on the underlying issue of interdisciplinary barriers and the subsequent difficulties it yields for sustainability education. The partnership and proposal ultimately resulted with an exercise that introduced building science methods into a history course in order to purposefully, and openly, show the value of holistic thinking

When the arts and humanities are combined with STEM (Science, Technology, Education, and Mathematics), there is believed to be a "two-way advantage" where both benefit (Connor, et al 2015,38). "The concept of STEAM education is emerging as a model of how boundaries between traditional academic subjects can be removed so that science, technology, engineering, arts and mathematics can be structured into an integrated curriculum. (Connor, et al 2015, 37)." Architectural education should embrace this model by bringing transdisciplinary methods into the classroom so that when students measure history they are doing more than completing an assignment, they are setting up an intellectual framework for capacious, sustainable design thinking, processes and results.

Keywords: Pedagogical innovations and research, sustainable design, history and theory of building technology, environmental design performance

\section{REFERENCES}

Altomonte, Sergio. "Enhancing Teaching and Learning of Sustainable Design through ICTs," presented at the ICETC International Conference on Education Technology and Computer, Shanghai, June 22-24, 2010.

Altomonte, Sergio, et al. "Mapping the Way Forward: Education for Sustainability in Architecture and Urban Design." Corporate Social Responsibility and Environmental Management 21 (2014): 143-154.

Boyer, Ernest. Scholarship Reconsidered: Priorities of the Professoriate. The Carnegie Foundation for the Advancement of Teaching, 1990.

Boyer, Ernest and Lee Mitgang. "Building Community: A New Future for Architecture Education and Practice: A Special Report." Carnegie Foundation for the Advancement of Teaching, 1996. 

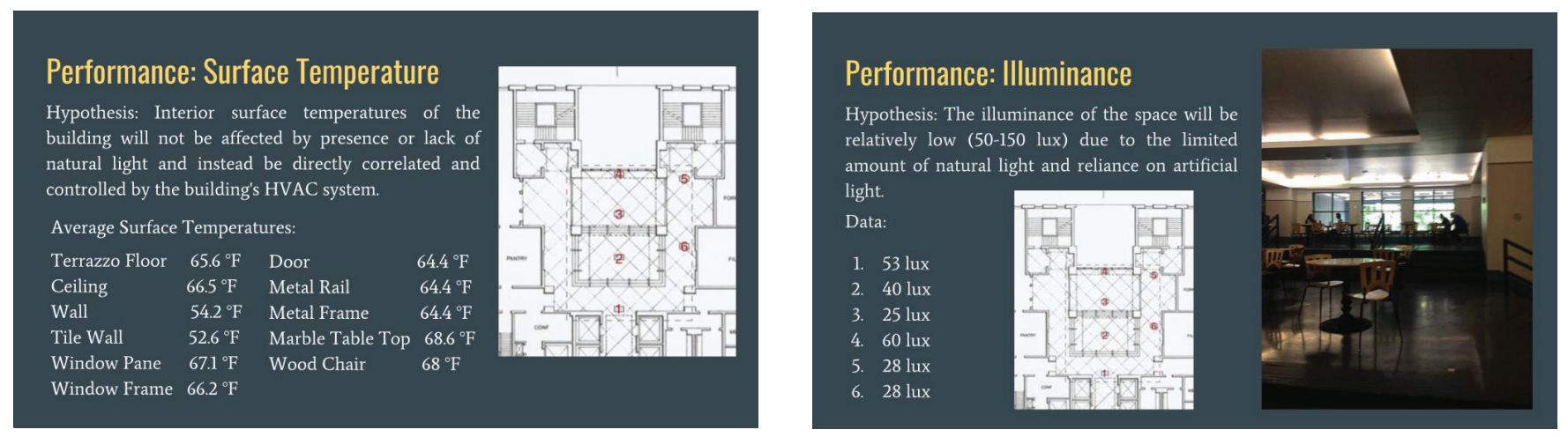

Figure 3. Sample images of student findings for Michael Graves’ postmodern Portland Building.

Boyer Commission on Educating Undergraduates in the Research University, Stoney Brook, NY. "Reinventing Undergraduate Education: A Blueprint for America's Research Universities." Carnegie Foundation for the Advancement of Teaching, 1998.

Brundiers, Katja. "Real-World Learning Opportunities in Sustainability: From Classroom into the Real World." International Journal of Sustainability in Higher Education 11, no. 4 (2010).

Cavanagh, Michael. "Students' Experiences of Active Engagement through Cooperative Learning Activities in Lectures." Active Learning in Higher Education 12, no. 1 (2011): 23-33.

Connor, A.M., et al., "From STEM to STEAM: Strategies for Enhancing Engineering \& Technology Education." International Journal of Engineering Pedagogies 5, no. 2 (2015): 37-47. http://dx.doi.org/10.3991/ijep.v5i2.4458.

Daugherty, Michael K. "The Prospect of an "A" in STEM Education." Journal of STEM Education 14, no. 2 (April - June 2013): 10-11.

de Haan, Gerhard. "The BLK '21' Programme in Germany: A 'Gestaltungskompetenz' Based Model for Education for Sustainable Development." Environmental Education Research 12, no. 1 (2006): 19-32.

Donofrio, Mark. "Building Knowledge: A Framework for a Translational Research Culture in Architecture." ARCC - The Visibility of Research (2013): 12-17.

Fernando, N. "The Ivory Tower and the Brick \& Mortar: Minding the Gap." Procedia Social and Behavioral Sciences 105 (2013): 48 - 53.

Graham, Peter. Building Ecology: First Principles for a Sustainable Built Environment. Hoboken, NJ: Wiley Blackwell, 2002.

Gelernter, Mark. "Reconciling Lectures and Studios." Journal of Architectural Education 41, no. 2 (1998): 46-52

Grant, Marcus, et al. "The Public Health Residency: a Novel Way to Focus Attention on Sustainability and Wellbeing in the Architectural Studio." Journal for Education in the Built Environment 7, no. 2 (2015): 84-109.

Gutierrez, Maria-Paz. "Reorienting Innovation: Transdisciplinary Research and Building Technology." Architectural Research Quarterly 18 (2014): 69-82. doi:10.1017/S1359135514000372.

Guy, Simon and Steven Moore. "Sustainable Architecture and the Pluralist Imagination." Journal of Architectural Education 60, no. 4 (2007): 15-23.

Harrison, Steven, et al. "It's Just a Method! A Pedagogical Experiment in Interdisciplinary Design." DIS 2006: Proceedings of the 6th Conference on Designing Interactive Systems. New York: ACM, 2006. 261-270.

Little, R.G. "Educating the Infrastructure Professional: A New Curriculum for a New Discipline." Public Works Management \& Policy 4 (1999): 93-99.

Kreber, Carolin, ed. The University and Its Disciplines: Teaching and Learning Within and Beyond Disciplinary Boundaries. Abingdon, UK: Routledge, 2009.

Kolb, David A. Experiential Learning: Experience as the Source of Learning and Development. Upper Saddle River, NJ: Prentice Hall, 1984.

Kolb, Alice, and David A. Kolb. "Learning Styles and Learning Spaces: Enhancing Experiential Learning in Higher Education." The Academy of Management Learning and Education 4, no. 2 (2005): 193-212.

Kuhn, Sarah. "Learning from the Architecture Studio: Implications for Project-Based Pedagogy." Int. J. Engng Ed. 17, nos. 4 and 5 (2001): 349-352

Martin, Leslie. "The History of the Idea of Research in Architecture: Reflections on the Value of Research." ARQ 20, no. 3 (2016): 189-191.

Meyers, Chet and Thomas B. Jones. Promoting Active Learning Strategies for the College Classroom. San Francisco: Jossey-Bass, 1993.
Smith, David Lee. "Integrating Technology into the Architectural Curriculum," Journal of Architectural Education 41, no. 1 (1987): 4-9.

Sutherland, Tracey E. "Emerging Issues in the Discussion of Active Learning Using Active Learning in College Classes." New Direction for Teaching and Learning 67 (1996): 83-95

Wetzel, Catherine. "Integrating Structures and Design in the First-Year Studio." Journal of Architectural Education 66, no. 1 (2012): 107-114.

Warburton, Kevin. "Deep Learning and Education for Sustainability." International Journal of Sustainability in Higher Education 4, no. 1 (2003): 44-56.

Xu, Ping. "Architectural and Landscape Design: A New Synthesis Major Proposed with Interdisciplinary and General Models." International Journal of Arts \& Sciences 5, no. 6 (2012): 369-388.

Yuretrich, Richard F. "Encouraging Critical Thinking: Measuring Skills in Large Introductory Sciences Classes." Journal of College Science Teaching 33, no. 3 (December 2003): 40-46 